\title{
Investigation of the Influence of Mineral Types on Surface Quality in the Case of Milled Granite Surface
}

\author{
Eszter Cserta $^{1}$, István Gábor Gyurika ${ }^{2}$ \\ ${ }^{1,2}$ University of Pannonia, Institute of Material and Mechanical Engineering \\ Egyetem str. 10, Veszprém, 8200 Hungary \\ ${ }^{1}$ cserta.eszter@mk.uni-pannon.hu \\ ${ }^{2}$ gyurika@almos.uni-pannon.hu
}

\begin{abstract}
The role of the application of various natural stone materials in the mechanical engineering and construction industries has steadily increased for the past few years. After the Fourth Industrial Revolution, the programmed CNC machines also came to the fore in the case of machining granites. Due to the development of machine tools, the surface quality of granites increased. As the granite has a heterogeneous grain structure, it is not possible to follow the formulas used in the machining of metals. We need to study the effects of the granite forming minerals on the surface roughness in order to achieve the surface quality determined by customer's needs. The research published in this article examines the surface damage of minerals in granite caused by the milling process. As a result of the research, we obtained an accurate picture of the effect of each mineral type on surface roughness and we were able to analyze the extent of the effect caused by each mineral on the surface. We are given a steady basis by the experiments presented in this article to design adequate surface quality and to develop a pre-estimation system.
\end{abstract}

Keywords: Surface roughness, Granite, Minerals, Scale, SEM, Confocal microscope

\section{Introduction}

Natural rocks are used more and more frequently in areas where dimensional accuracy and the adequate surface quality are also of high priority. Such products include sculptures and tabletops in the construction industry and CNC coordinated measuring machine tables and ultra-precision lathe pillow in the mechanical engineering industry. In the case of different granite products, it is important to highlight the heterogeneity and the differences of the size and fracture properties of the minerals that form the rocks. The aim of the research presented in this article is to examine the extent to which rock forming minerals affect the surface quality in the case of milling process of natural granites. A light microscope, a scanning electron microscope, X-ray diffractometer and confocal microscope were used in the research. The stripes on the surface of the selected rocks were formed at the same six speed. Following the milling process, a detailed study was prepared on the effect of different minerals on surface roughness where the effect was determined by a confocal microscope. As a result of the investigations, we were able to set out an order of the effect of the investigated minerals on the surface quality.

\section{Literature research}

Many researchers studied the granite and its surface quality, which is mostly reduced by the appearance of cracks. Tian and colleagues [1] investigated the behavior of non-coplanar cracks at uniaxial pressure. The result of the experiment showed that sample with larger particle size causes fewer cracks. Homand et al.[2] make investigations at constant temperatures but at different stress levels. These investigations proved the appearance of new cracks and not the growth of earlier cracks. In additional, freshly appeared cracks often meet. Other researchers focused on the temperature and they found that high temperature and high-speed heating are necessary for cracks to form[3]. This statement is also supported by Zhang et al.[4] who stated that temperature change affects rock properties. Meanwhile, Huang and his team [5] examined the cavities in the rocks. As the shape of the cavity moves from the oval shape to the circle, the compressive strength of the uniaxial also increases. The value of the triaxial pressure decreases only if the density of microcracks in the sample is high [6]. There is a correlation between the strength of rocks, the density of microcracks and their length [7].

The strength of the rocks is affected not only by the microcracks, but also the properties of the rock forming minerals. Prikryl studied the physical parameters of constituent minerals such as their size and its distribution, their shape, their orientation and composition. According to Prikryl, if the size of the particles decreases, their strength will be higher [8]. Strength also greatly affects the machinability of rocks, and thus the quality of the surface. The degree of 
surface roughness is an important factor for both using and machining. The main information is how much material needs to be removed during surface design [9] because both the rock and the machining process have high costs. Their study showed that the rock forming minerals and their structures are the primary factors influencing the formation of the appropriate surface.

Huang and $\mathrm{Xu}$ studied the gloss of a granite surface and they found that it increases when surface roughness decreases. Roughness and brightness are exponentially related. When the roughness of the granite exceeds $0.2 \mu \mathrm{m}$ during the machining of granite, the material detachment is caused by fracture. This phase is the crushing grinding phase. In this phase, the brightness changes in a small extent while the roughness changes greatly, which is caused by rough surface grinding. When Huang and $\mathrm{Xu}$ reduced the size of the diamond grains in the machining tool, the roughness of the granite gave a value below $0.2 \mu \mathrm{m}$, and the plastic deformation prevailed. This is the plastic deformation stage. At this stage, the gloss of the surface can be greatly increased, while the roughness decreases only slightly. These results are influenced by different crystal structure and crystal properties [10]. In contrast, in Aydin and his research team's opinion the grain size is an important parameter [11].

Saidi et. al. studied the polishing of granite. During the polishing process, two material removal mechanisms were detected and distinguished, where the development of pressure and coefficient of friction were also taken into consideration. One of the two material removal mechanisms is at the beginning of the granite polishing process, in which a grinding wheel containing less than 400 diamond grains was used, which caused brittle fracture due to an increase in the coefficient of friction and a decrease in surface pressure. The other mechanism occurred at the second half of the polishing process, in which a disc with more than 400 grains was used, which caused plastic working. Saidi et. al. also found that the average surface roughness $R_{a}$ and the depth of roughness $R_{t}$ vary depending on the particle size [12].

Another experiment studied the important granite forming minerals. After analyzing the experimental data, the researchers concluded that the components mostly influencing the wear performance of the saw blade are quartz and alkaline feldspars (orthoclase, microcline). According to the researchers, the criterion for the wear performance of the sawblade is SWR (Specific Wear Rate Index). The relationship between the plagioclase feldspar, the grain size and SWR was examined. There is a relatively weak correlation between quartz and SWR, which means that quartz content alone does not significantly affect saw blade wear. Except for Shore hardness, none of the examined physical and mechanical properties showed a significant correlation with SWR, suggesting that physical and mechanical properties are not influencing factors for diamond tool wear. Further investigation was carried out on the grains size. Large quartz grains and K-feldspar grains were found to be important petrological variables that influence the extent of SWR. In addition, the average particle size had a small effect on the SWR value, in contrast to the large particle size. The abrasive effect of the larger grains is higher, which was also confirmed by measurements. When granite blocks containing a small amount of quartz were used to perform the experiments, the sawblade was less worn. This observation showed that the material grouping is an important process when the relationship between the wear performance of the blades and the petrological properties of the granite are examined [13].

Other researchers studied the amount of quartz minerals in rock and they found a correlation between quartz content and workability [14]. Consistent with the results of Aydin et. al [11] (the grain size is an important influencing parameter), and research of Prikryl [8] (strength is a determining property) the same influencing properties (grains size, hardness, strength) were found for quartz mineral [14], which means that the efficiency of machining increases with decreasing hardness [15].

\section{Materials and method}

Figure 1. shows the process of the research, which includes each of the implemented phases. An important criterion was to have as many different types of minerals as possible in the selected samples. Based on these criteria, 5 rock blocks (Fig. 1 (I.)) were analyzed with a light microscope (Fig. 1 (III.)), a scanning electron microscope (Fig. 1 (IV.)) and an X-ray diffractometer (Fig. 1 (V.)), and then 3 samples were selected (Fig. 1 (VI.)), which cover all types of classification based on average particle sizes - fine grains, medium and coarse grains - and most different minerals. 


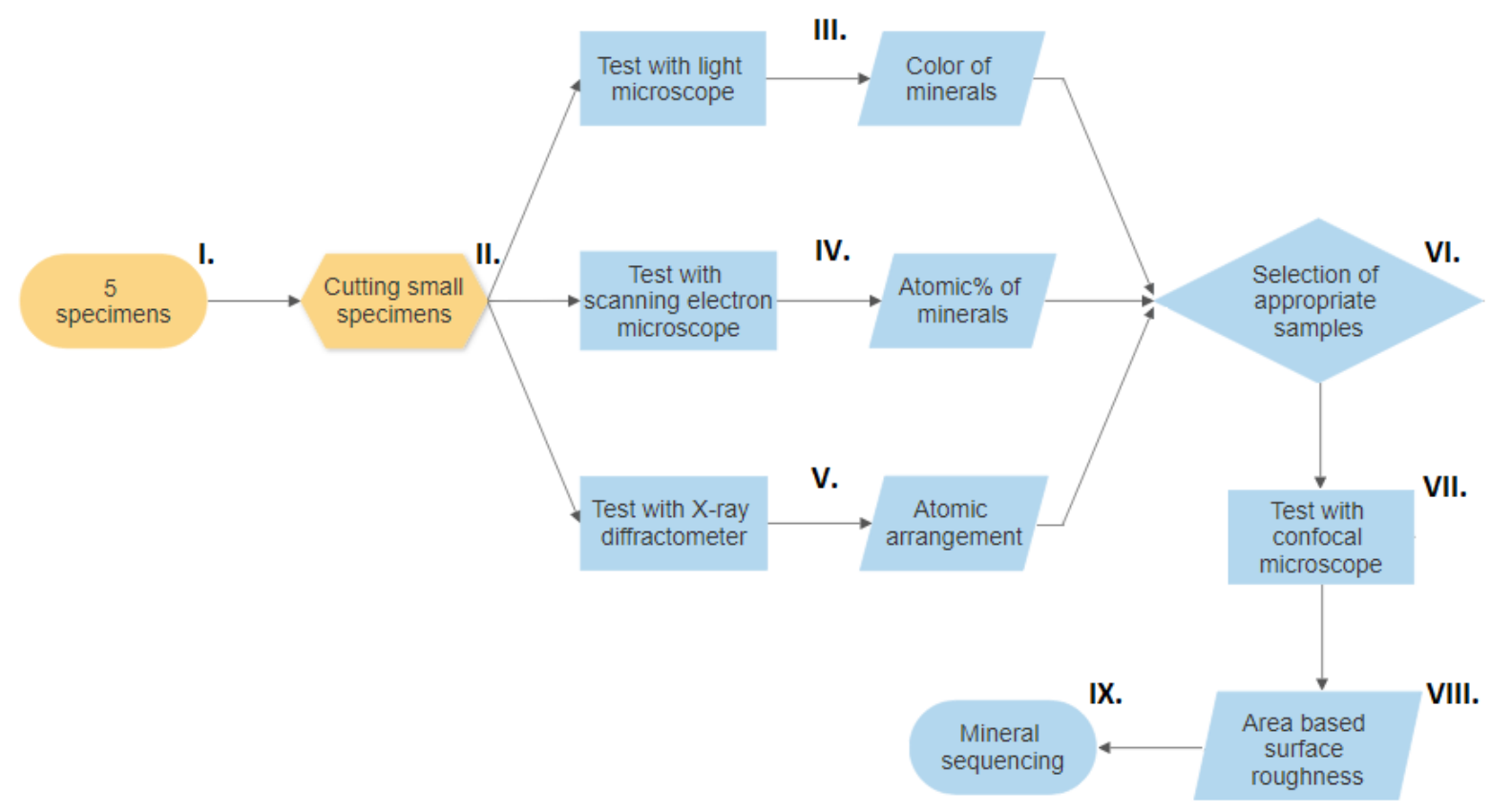

Fig. 1: Process of the research.

As a result of the measurements, we determined the material composition of the samples in order to measure the surface roughness of the minerals in the corresponding samples during the experiment.

For the measurements, $4 \times 4 \times 2$ small samples were cut from the blocks (Fig. 1 (II.)) so that they could be placed on the stages of different machines. We examined the samples with a light microscope first. A KEYENCE VHX 2000 ultraprecision light microscope was used for the measurement (Fig. 1 (III.)). It was used to determine the color of the minerals on the surface of the different granite samples (Fig. 2). This step was important because in a later study, when measuring the surface roughness, we identified the minerals based on their unique color.

During the study, the following colored minerals were distinguished on the three selected granite samples:

o black

- ivory/white

$\circ$ gray

- rose color

- colorless/off-white

$\circ$ yellowish. 


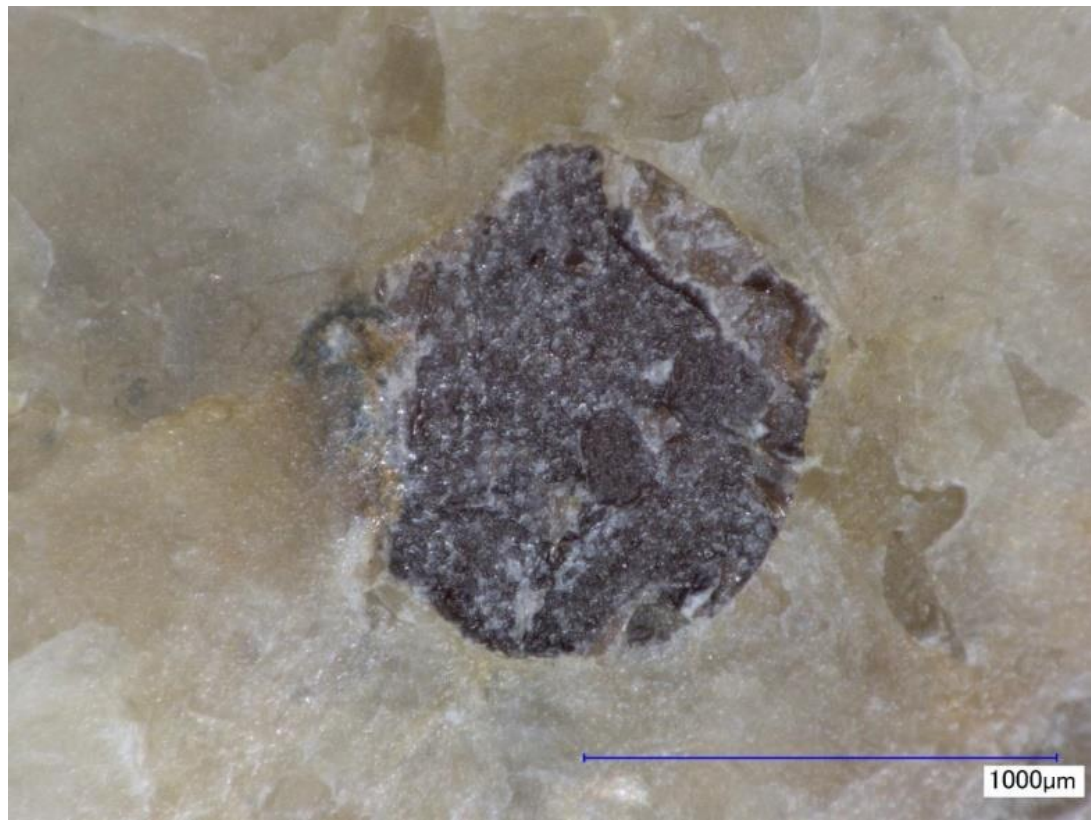

Fig. 2: Light microscopic image of Sample 2.

The color determination was followed by elemental composition analysis, in which samples were transferred from the light microscope to FEI/Thermofisher Apreo S, Philips XL 30 ESEM scanning electron microscope (Fig. 1 (IV.)). We cleaned the surfaces of the samples with compressed air to remove contaminants and we examined the elemental composition of minerals whose color was previously identified by a light microscope. This method is shown in Figures 2 and 3. In the light microscope, the brown mineral and the yellowish mineral were examined and then the atomic percentage composition of minerals was measured by a scanning electron microscope. Thus, we could attach an elemental composition to the established colors, which was analyzed with XRD later.

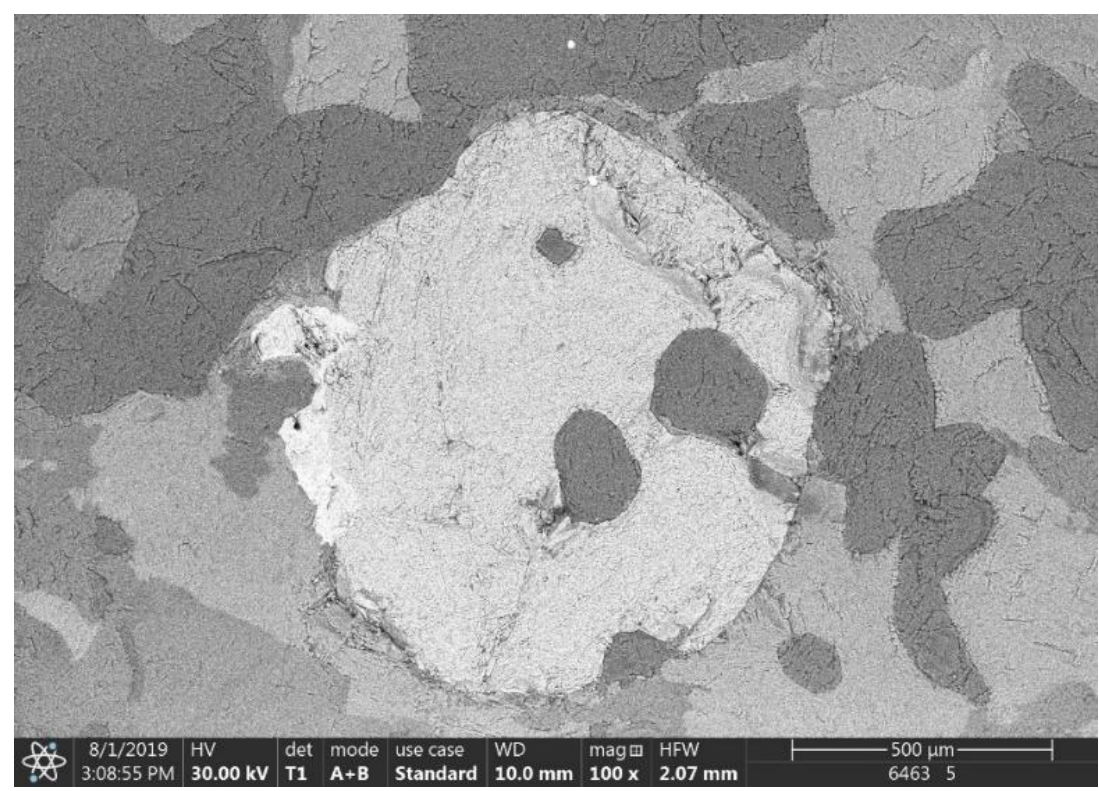

Fig. 3: Scanning electron microscopic image of Sample 2 in Fig. 2.

In Figure 3., the SEM micrograph clearly shows the boundaries of the different minerals. It is easier to identify the boundaries of the different minerals in the image taken by a SEM than in the light microscopic image. With the help of the SEM software, the elemental composition of arbitrarily selected areas can be determined, so we can measure any shade of the black-and-white image.The device can also visualize the roughness of the surface, but cannot associate a relevant value with it. 


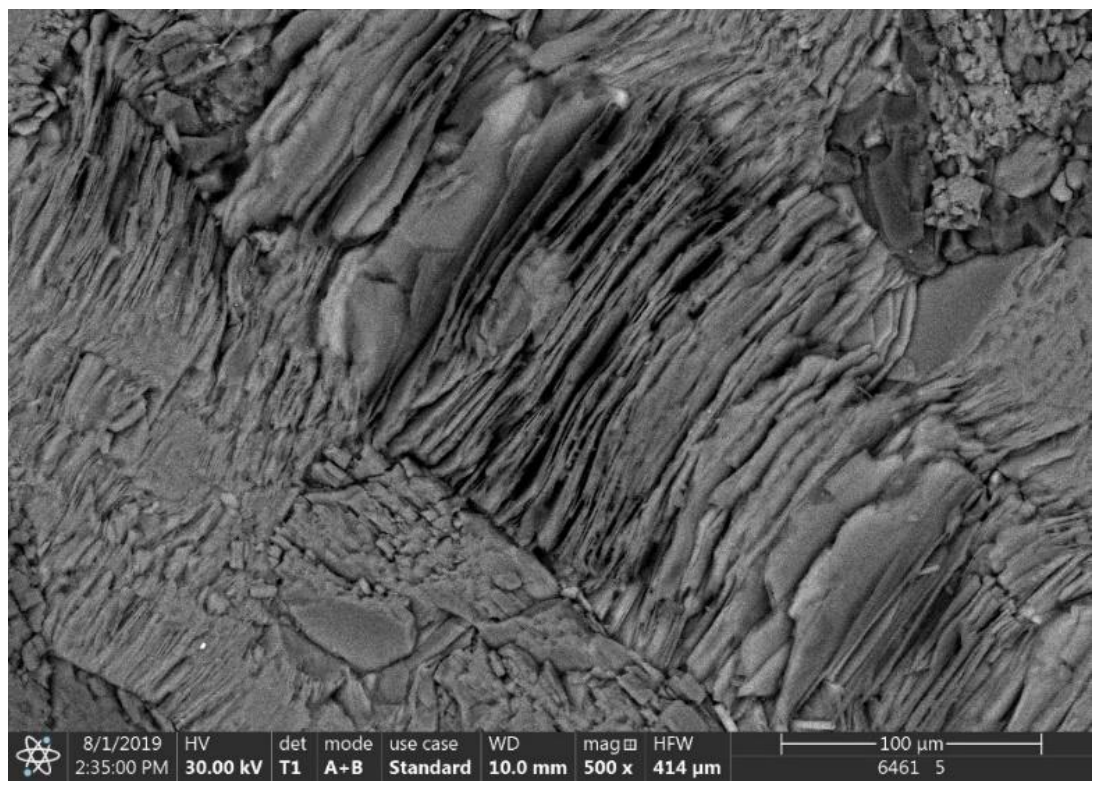

Fig. 4: SEM image shows surface roughness.

We can clearly see on Figure 4., even without accurate figures, that different minerals have different surface roughness so different minerals affect the surface roughness in different ways. We could observe that the formed surface became very smooth when the rock fractured. However, without fractures the machined surface showed a higher roughness value.

In order to check the results of the scanning electron microscope and the accuracy of the elemental composition, we examined the samples by using an X-ray diffractometer (Fig. 1 (V.)). Before this step, the samples were pulverized below $63 \mu \mathrm{m}$ particle size. The powder was measured, and the elemental composition of the different colored minerals was determined together with the SEM results. Depending on the results, different rocks were selected so that we could examine as many different minerals in the samples as possible.

The minerals shown in Table 1 were present in the selected samples:

Table 1: Name of minerals with different color in the investigated samples.

\begin{tabular}{|l|l|l|}
\hline 1. & Black & biotite \\
\hline 2. & ivory/white & albite \\
\hline 3. & gray & quartz \\
\hline 4. & rose color & orthoclase \\
\hline 5. & colorless/off-white & labradorite \\
\hline 6. & yellowish & microcline \\
\hline
\end{tabular}

The determination of the minerals forming the surface of the selected specimens (Fig. 1 (VI.)) was followed by the examination of the surface roughness of the minerals (Fig. 1 (VII.)). Measurements were performed with an Alicona InfiniteFocus IFM G4confocal microscope at resolution of $10 \mathrm{~nm}$. The minerals on the surface of the specimens were distinguished based on their unique colors and the surface roughness of the minerals was measured accordingly.

On the surface of each sample, six stripes machined at different milling speeds were formed. Only this one parameter changed during machining. The cutting speeds were as follow:

Stripe $1: 37.7 \mathrm{~m} / \mathrm{min}$

Stripe $2: 75.4 \mathrm{~m} / \mathrm{min}$

Stripe 3: $113.1 \mathrm{~m} / \mathrm{min}$

Stripe 4: $150.8 \mathrm{~m} / \mathrm{min}$

Stripe 5: $188.5 \mathrm{~m} / \mathrm{min}$

Stripe 6: $226.2 \mathrm{~m} / \mathrm{min}$.

During the experiment, surface-based roughness was measured versus line-based because we could get more accurate results. 


\section{Results and discussion}

The surface roughness of different minerals was measured in each line. The results are shown in the diagrams below (Fig. 5):
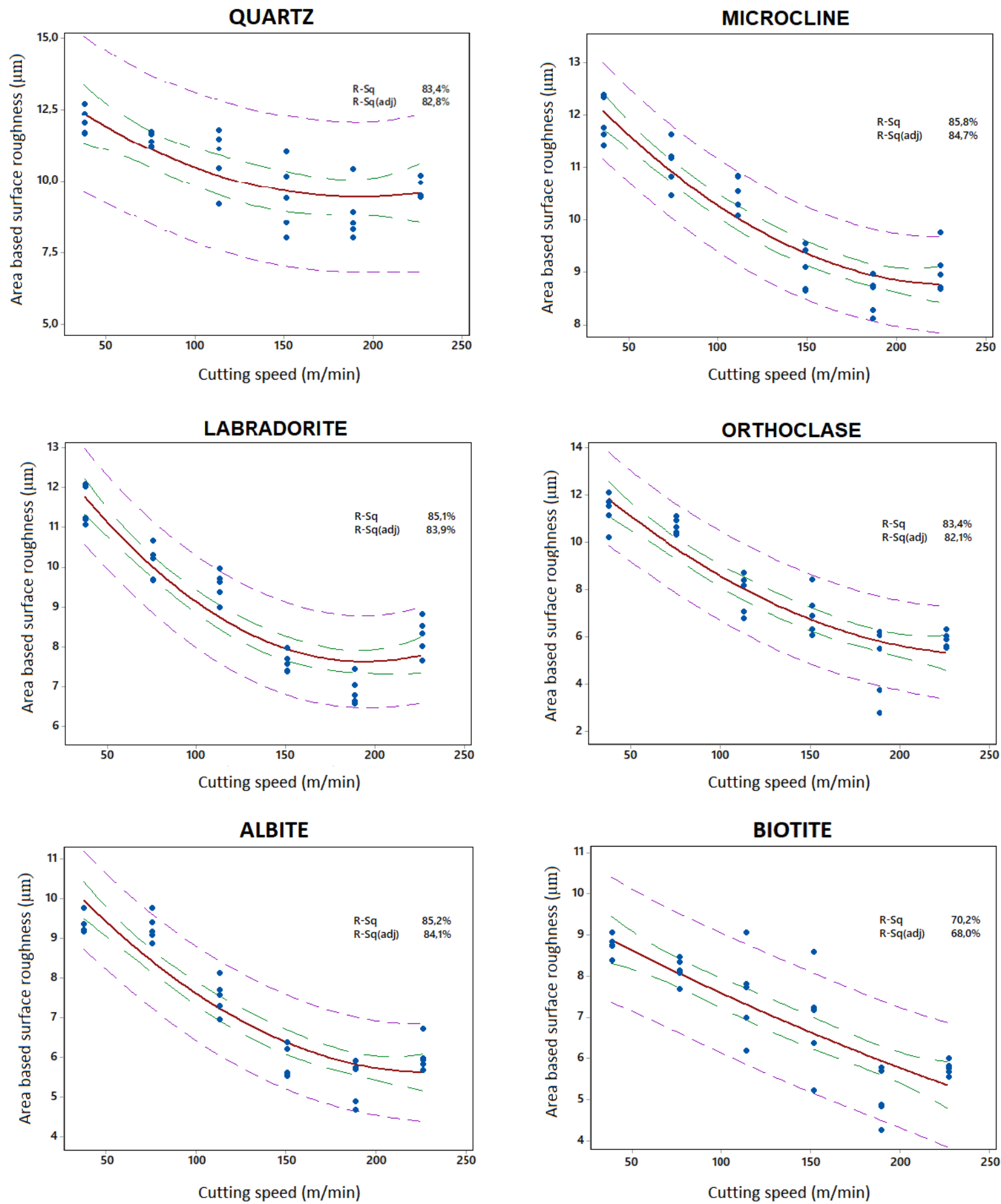

Fig. 5: Effect of the different samples forming minerals on surface roughness.

The results showed a strong correlation for all minerals $\left(R^{2}=0.70-0,85\right)$, which was statistically significant $(P=0.003-0.018)$.

After statistical evaluation, the minerals were ranked according to their effect on surface roughness. The main point of ranking is the relationship of minerals to each other. The results shown in the diagrams suggest that the quartz mineral has the roughest surface. The value of the quartz's surface roughness is followed by the value of the feldspars. The values of the feldspars are relatively close to each other, but the different minerals form well-separable sets. Feldspars are important natural materials, and many researchers pay attention to them [16], so the proper treatment of 
their surface is an important aspect in the categories of rock processing. In terms of surface quality, the surface of the biotite was the least rough.

Evaluating the results, we were able to determine the following order $\left(1^{\text {st }}\right.$ causing the roughest surface; $6^{\text {th }}$ causing the smoothest surface):
$1^{\text {st }}$ quartz
$2^{\text {nd }}$ microcline
$3^{\text {rd }}$ labradorite
$4^{\text {th }}$ orthoclase
$5^{\text {th }}$ albite
$6^{\text {th }}$ biotite.

The established order, which shows the effect of minerals on the surface roughness, does not follow the order established above for all cutting speeds. However, this problem is true only for a few cutting speeds and minerals. During our evaluation, we took the average of the values as a basis, and we established the relative order based on those values.

\section{Conclusion}

The use of the natural rocks is gradually increasing as a result of the Fourth Industrial Revolution. Granite has a heterogeneous grain structure, due to which the surface treatment methods applied for the most typical materials (metals) in the industry cannot be used.

The effect of granite forming minerals on surface roughness is an important factor for different customer needs. During the experiments, plenty of devices were used to make a detailed research. A light microscope, a scanning electron microscope, an X-ray diffractometer and a confocal microscope were used. In the experiment, the effect of different minerals on surface roughness and their relative values were investigated. The results showed that the roughest surface was caused by quartz and the smoothest by biotite. The feldspar minerals were located between the two values; the microcline had the roughest surface, followed by albite and then labradorite. The smoothest feldspar surface was obtained by the orthoclase. These studies provide a great basis for setting up a forecasting system.

\section{Acknowledgements}

We wish to express our gratitude to teachers Mihály Pósfai DSc and Kristóf Kovács CSc and PhD student Miklós Jakab at University of Pannonia for their help with the measurement and evaluation process.

We acknowledge the financial support of the Peregrinatio Foundation and MOL Corporation.

\section{References}

[1] W.-L. Tian, S. Q. Yang, L.-X. Xie, and Z.-L. Wang, "Cracking behavior of three types granite with different grain size containing two non-coplanar fissures under uniaxial compression," Arch. Civ. Mech. Eng., vol. 18, no. 4, pp. 1580-1596, 2018.

[2] F. Homand, D. Hoxha, T. Belem, M.-N. Pons, and N. Hoteit, "Geometric analysis of damaged microcracking in granites," Mech. Mater., vol. 32, no. 6, pp. 361-376, 2000.

[3] F. Wang, H. Konietzky, T. Frühwirt, Y. Li, and Y. Dai, "Impact of cooling on fracturing process of granite after high-speed heating," Int. J. Rock Mech. Min. Sci., vol. 125, no. July 2019, p. 104155, 2020.

[4] F. Zhang, Y. Zhang, Y. Yu, D. Hu, and J. Shao, "Influence of cooling rate on thermal degradation of physical and mechanical properties of granite," Int. J. Rock Mech. Min. Sci., vol. 129, no. May 2019, p. 104285, 2020.

[5] Y.-H. Huang, S.-Q. Yang, M. R. Hall, W.-L. Tian, and P.-F. Yin, "Experimental study on uniaxial mechanical properties and crack propagation in sandstone containing a single oval cavity," Arch. Civ. Mech. Eng., vol. 18, no. 4, pp. 1359-1373, 2018.

[6] A. Golshani, Y. Okui, M. Oda, and T. Takemura, "A micromechanical model for brittle failure of rock and its relation to crack growth observed in triaxial compression tests of granite," Mech. Mater., vol. 38, no. 4, pp. 287-303, 2006.

[7] M. H. B. Nasseri, B. Mohanty, and P.-Y. F. Robin, "Characterization of microstructures and fracture toughness in five granitic rocks," Int. J. Rock Mech. Min. Sci., vol. 42, no. 3, pp. 450-460, 2005.

[8] Prikryl R., "Some microstructural aspects of strength variation in rocks," Int. J. Rock Mech. Min. Sci., vol. 38, no. 5, pp. 671-682, 2001.

[9] R. P. Ribeiro and A. B. Paraguassú, "Relationship between technological properties and slab surface roughness of siliceous dimension stones," Int. J. Rock Mech. Min. Sci., vol. 45, no. 8, pp. 1526-1531, 2008. 
[10] H. Huang and X. P. Xu, "Interfacial interactions between diamond disk and granite during vertical spindle grinding," An Int. J. Sci. Technol. Frict. Lubr. Wear, vol. 256, no. 6, pp. 623-629, 2004.

[11] G. Aydin, I. Karakurt, and K. Aydiner, "Investigation of the surface roughness of rocks sawn by diamond sawblades,” Int. J. Rock Mech. Min. Sci., vol. 61, pp. 171-182, 2013.

[12] M. N. Saidi, V. Songmene, J. Kouam, and A. Bahloul, "Experimental investigation on fine particle emission during granite polishing process," Int. J. Advenced Manuf. Technol., vol. 81, no. 9-12, pp. 2109-2121, 2015.

[13] N. G. Y1lmaz, R. M. Goktan, and Y. Kibici, "An investigation of the petrographic and physico-mechanical properties of true granites influencing diamond tool wear performance , and development of a new wear index," Int. J. Sci. Technol. Frict. Lubr. wear, vol. 271, no. 5-6, pp. 960-969, 2011.

[14] X. Wei, C. Y. Wang, and Z. H. Zhou, "Study on the fuzzy ranking of granite sawability," J. Mater. Process. Tech., vol. 139, no. 1-3, pp. 277-280, 2003.

[15] J. Xie and J. Tamaki, "Parameterization of micro-hardness distribution in granite related to abrasive machining performance," J. Mater. Process. Tech., vol. 186, no. 1-3, pp. 253-258, 2007.

[16] Y. Zhang, Y.Hu, N. Sun, r. Liu, Z. Wang, L. Wang, and W. Sun, "Systematic review of feldspar beneficiation and its comprehensive application," Miner. Eng., vol. 128, pp. 141-152, 2018. 